\title{
Distributional patterns of a marine bird and its prey: habitat selection based on prey and conspecific behaviour
}

\author{
Gail K. Davoren ${ }^{1, *}$, William A. Montevecchi ${ }^{1}$, John T. Anderson ${ }^{2}$ \\ ${ }^{1}$ Biopsychology Programme, Departments of Biology and Psychology, Memorial University of Newfoundland, St. John's, \\ Newfoundland A1B 3X9, Canada \\ ${ }^{2}$ Northwest Atlantic Fisheries Centre, Fisheries and Oceans Canada, St. John's, Newfoundland A1C 5X1, Canada
}

\begin{abstract}
We examined distributional patterns of a pursuit-diving seabird, the common murre Uria aalge, and its fish prey, capelin Mallotus villosus, within the avian foraging range of the largest murre colony in eastern North America: Funk Island, Newfoundland. During chick-rearing, the foraging habitat was previously partitioned into: (1) a high-quality area, $45 \mathrm{~km}$ from the colony where energyrich capelin schools were found, which were spatially and temporally persistent and (2) a low-quality area, $60 \mathrm{~km}$ from the colony where schools were composed of lower-energy capelin that were ephemeral. At the scale of the foraging range (meso-scale: 1 to $100 \mathrm{~km}$ ), murres were highly clustered into $25 \%$ of the surveyed area, with fewer murres in the low-quality relative to the high-quality area. There were tighter associations among murre and capelin aggregations in the low-quality $(1.2 \pm$ $0.2 \mathrm{~km})$ relative to the high-quality area $(2.6 \pm 0.4 \mathrm{~km})$. This likely resulted from the divergent capelin behaviour and, thus, different foraging strategies used by murres to search for (e.g. memory vs local enhancement) and capture prey. At fine spatial scales $\left(250 \mathrm{~m}^{2}\right)$ within foraging areas, murres were found at lower densities (mode: 2 murres), revealing that interference competition among individuals may be important during prey capture. Modeling revealed that at $>50$ murres per $250 \mathrm{~m}^{2}$ in the highquality area, a murre would have a $>90 \%$ chance of increasing its foraging efficiency by switching to forage in the low-quality area. Overall, this scale-dependent aggregative behaviour of murres suggests that cooperative foraging among conspecifics may be important in locating prey at the scale of a foraging range, or murres may simply aggregate in areas of high prey abundance, but competitive interactions among conspecifics become important at the scale of prey capture.
\end{abstract}

KEY WORDS: Habitat selection - Scale $\cdot$ Predator-prey theory $\cdot$ Competition $\cdot$ Model $\cdot$ Ideal free distribution $\cdot$ Common murre $\cdot$ Capelin

Resale or republication not permitted without written consent of the publisher

\section{INTRODUCTION}

Distributional patterns of animals generally reflect how individuals meet their energetic requirements for survival (Horne \& Schneider 1994). Animals likely assess many criteria on multiple temporal and spatial scales in order to distribute themselves appropriately among available habitats (Fretwell \& Lucas 1970). Depending on current metabolic demands, prey conditions could be the most important determinant of animal distribution patterns. Prey conditions include prey availability, density, and behaviour (e.g. persistence of an aggregation in space and time), composition of prey types, and the rate of change of prey availability and abundance (Harper 1982, Croy \& Hughes 1991). Distributional patterns of predators relative to their prey, or the scale at which predator and prey aggregations overlap (tracking scale), also reflect how animals meet their energetic requirements (Horne \& Schneider 1994). Tracking scales of mobile predators to prey are highly variable, and characteristic scales of association are rarely identified (e.g. Schneider \& Piatt 1986). 
Studying tracking scales under periods of different prey conditions or energetic demands, however, allows the elucidation of individual-level foraging behaviour and population-level habitat selection (e.g. Davoren et al. 2002).

Many theoretical frameworks assess the mechanisms underlying distributional patterns of mobile predators. For colonial animals that must return to a breeding site to deliver food to offspring (i.e. centralplace foragers), provisioning rates are limited by the time spent during a round trip from the breeding site. The central-place foraging model (Orians \& Pearson 1979) predicts that colonial animals minimize the duration of round trips by foraging close to the colony, resulting in conspecifics becoming concentrated within a restricted foraging range (Cairns \& Schneider 1990, Mehlum et al. 1996, Maniscalco et al. 1998). Therefore, habitat selection by a colonial animal likely depends on the choices of conspecifics as well as prey conditions within foraging ranges (Hunt et al. 1986, Birt et al. 1987, Miliniski \& Parker 1991, Grunbaum \& Veit in press). Conspecifics can increase encounter rates with prey by cueing to the foraging activities of other animals (local enhancement; Wittenberger \& Hunt 1985, Grunbaum \& Veit in press), and can increase consumption rates through cooperative foraging (e.g. herding prey; Angell \& Balcomb 1982). Alternately, conspecifics can reduce consumption rates by reducing encounter rates with prey (exploitative or scramble competition) or by altering behaviour independent of prey availability through aggressive interactions or avoidance behaviour (interference or contest competition; Hunt et al. 1986, Milinski \& Parker 1991, Stillman et al. 1996, Cresswell 1997, Hughes 1997, Maniscalco et al. 2001).

Within foraging ranges of colonies, the ideal free distribution theory (IFD; Fretwell \& Lucas 1970) can be used to link behavioural foraging theory and predatorprey theory within a spatial context of habitat selection over heterogeneous landscapes (Huntingford 1993, Miliniski 1994). IFD models assume that animals have complete knowledge of all prey patch locations and qualities, are 'free' to exploit any available patch without restriction, distribute themselves 'ideally' among these patches to obtain the highest foraging efficiencies (i.e. prey intake rates), and all animals are assumed to have similar average foraging efficiencies among patches (Fretwell \& Lucas 1970, Sutherland 1983, Parker \& Sutherland 1986). The underlying premise of IFD models is that predator populations are subject to density-dependent control due to small-scale interactions within prey patches (Fretwell \& Lucas 1970, Tregenza 1995), and although individual benefits may increase as competitor density increases up to some maximum, they will decrease thereafter (Allee 1931).
The common murre Uria aalge is a pursuit-diving marine bird that dives to depths up to $200 \mathrm{~m}$ (Piatt \& Nettleship 1984). Murres hunt visually and forage primarily during daylight (Swennen \& Duiven 1991). Their wing design compromises aerial (high surface area) and underwater flight (low surface area; Thompson et al. 1998) and results in high wing-loading (i.e. body mass to wing area ratio: $2.06 \mathrm{~g} \mathrm{~cm}^{-2}$; Guillemette 1994). Therefore, energy expenditure is elevated during flight compared to most other seabirds. Murres are highly colonial and lay a single-egg clutch. The chick is reared at the colony by both parents for $3 \mathrm{wk}$. One parent remains at the colony with the chick while the other is on a foraging trip. Foraging trips in eastern Canada generally last $4 \mathrm{~h}$ (Davoren \& Montevecchi 2003) and are $<100 \mathrm{~km}$ (Cairns et al. 1987). After most foraging trips, the parent delivers a single fish to its chick. In Newfoundland, murres feed their chicks forage fish, primarily capelin (Mallotus villosus; Davoren \& Montevecchi 2003). As central-place foragers, the amount of food delivered to chicks each day, and their subsequent probability of survival, depends on the quality of fish and the frequency of fish deliveries (Davoren 2001).

In previous work, we described the characteristics of the foraging environment available to common murres around Funk Island, the largest murre colony in eastern North America (Table 1). We identified 2 general areas with above-average abundances of capelin during a vessel survey within the foraging range of chickrearing murres from Funk Island (Fig. 1). The closest area to the colony, or persistent area, had a consistently high abundance and persistent presence of capelin on a temporal scale of $2 \mathrm{wk}$ (Table 1). Capelin schools in this area were near the seabed in deep (>50 m) water, were composed of equal proportions of maturing male and female capelin, and were located in the same position on different days (persistent schools; Table 1). The farther, or ephemeral, area had fluctuating abundances and inconsistent presence of capelin (Table 1). Capelin schools in this area were situated in the water column in shallow $(<50 \mathrm{~m})$ water, were predominantly composed of spent female capelin and were always ephemeral in space on the temporal scale of minutes (Table 1). The implication of this prey behaviour was that murres use different search strategies to locate capelin schools in the persistent area (memory) relative to the ephemeral area (local enhancement; Davoren et al. in press). Both areas had similar mean abundances of capelin, although variability in abundance was higher in the ephemeral compared to the persistent area (Table 1). The abundance of murres in the persistent area was an order of magnitude higher than in the ephemeral area, although murre abundance was highly variable in both areas. 
Table 1. Uria aalge. A comparison of the habitat characteristics of the persistent and ephemeral foraging areas of common murres around the Funk Island colony. Information from Davoren (2001) includes the persistence of capelin and murre presence per $2.25 \mathrm{~km}$ 'hot spot' (areas with above average abundance scores of capelin) and the range of mean \pm SE abundance scores of capelin and the mean \pm SE abundance of murres per $2.25 \mathrm{~km}$ hot spot in the persistent and ephemeral foraging areas. Mean abundance for all $2.25 \mathrm{~km}$ foraging areas during the broad-scale survey was $2.9 \pm 0.5$ murres and $0.8 \pm 0.1$ (acoustic abundance score) capelin

\begin{tabular}{|lcc|}
\hline Characteristics & Persistent area & Ephemeral area \\
\hline Distance from colony $(\mathrm{km})$ & 45 & 60 \\
Distance from shore $(\mathrm{km})$ & 30 & 10 \\
Capelin composition & Maturing males and females & Spent females \\
School type composition & Persistent: $301 \pm 48$ fish m $^{-2}$ & Ephemeral: $201 \pm 44$ fish $\mathrm{m}^{-2}$ \\
Persistence of capelin presence per $2.25 \mathrm{~km}$ & $100 \%$ & $25-100 \%$ \\
Persistence of murre presence per $2.25 \mathrm{~km}$ & $100 \%$ & $50-100 \%$ \\
Abundance score of capelin per $2.25 \mathrm{~km}$ (scale: $0-9)$ & $1.1 \pm 0.3$ & $0.3 \pm 0.2$ \\
& $-1.2 \pm 0.2$ & $-1.0 \pm 0.9$ \\
Abundance of murres per $2.25 \mathrm{~km}$ & $3.0 \pm 2.4$ & $0.3 \pm 0.3$ \\
No. of $2.25 \mathrm{~km}$ hot spots & $-17.6 \pm 13.0$ & $-3.0 \pm 2.9$ \\
\end{tabular}

Based on this information, we examined the distribution patterns of murres and capelin in order to explore the underlying behavioural mechanisms contributing to selection between the 2 foraging areas within the murres' foraging range from Funk Island. The first objective was to describe broad-scale distribution patterns of murres and capelin around the colony, using nearest neighbour univariate techniques (Ripley 1981, O'Driscoll 1998). We also used bivariate techniques to describe the extent of spatial overlap among aggregations of murres and capelin and to explore individuallevel foraging behaviour resulting in population-level distributional patterns. The second objective was to explore how proximity to the colony combined with prey and conspecific behaviour resulted in selection between the 2 foraging areas through a simple model, which was based on IFD theory. Linking population-level distributional patterns and predator-prey spatial associations with energetic considerations of predators provides a useful framework with which to examine factors that influence habitatselection decisions by individuals (Horne \& Schneider 1994, Wanless et al. 1997).

\section{MATERIALS AND METHODS}

Study area. A meso-scale (1 to $800 \mathrm{~km}$ ) vessel survey was conducted within avian foraging ranges around the Funk Island Seabird Ecological Reserve $\left(49^{\circ} 45^{\prime} \mathrm{N}, 53^{\circ} 11^{\prime} \mathrm{W}\right)$ off the east coast of Newfoundland in the northwest Atlantic (Fig. 1). Funk Island lies approximately $60 \mathrm{~km}$ from the coast and 340000 to 400000 pairs of common murres breed there (Cairns et al. 1989). Funk Island is the largest breeding colony of common murres in eastern north America and represents $75 \%$ of the northwest Atlantic population (Cairns et al. 1989). A small colony of common murres is located $150 \mathrm{~km}$ south of Funk Island (Cabot Island: 2600 breeding pairs). Flight patterns observed at sea revealed that foraging zones or hinterlands (Cairns 1989) do not overlap (Davoren et al. in press).

Survey design. The $5 \mathrm{~d}$ broad-scale survey consisted of 9 east-west (across shelf) hydroacoustic transects at a 5 nautical mile $(9 \mathrm{~km})$ north-south spacing. The survey was carried out aboard a $23 \mathrm{~m}$ Fisheries Canada RV 'Shamook' that operated $12 \mathrm{~h} \mathrm{~d}^{-1}$. Seabirds were counted continuously during acoustic transects. A nav-

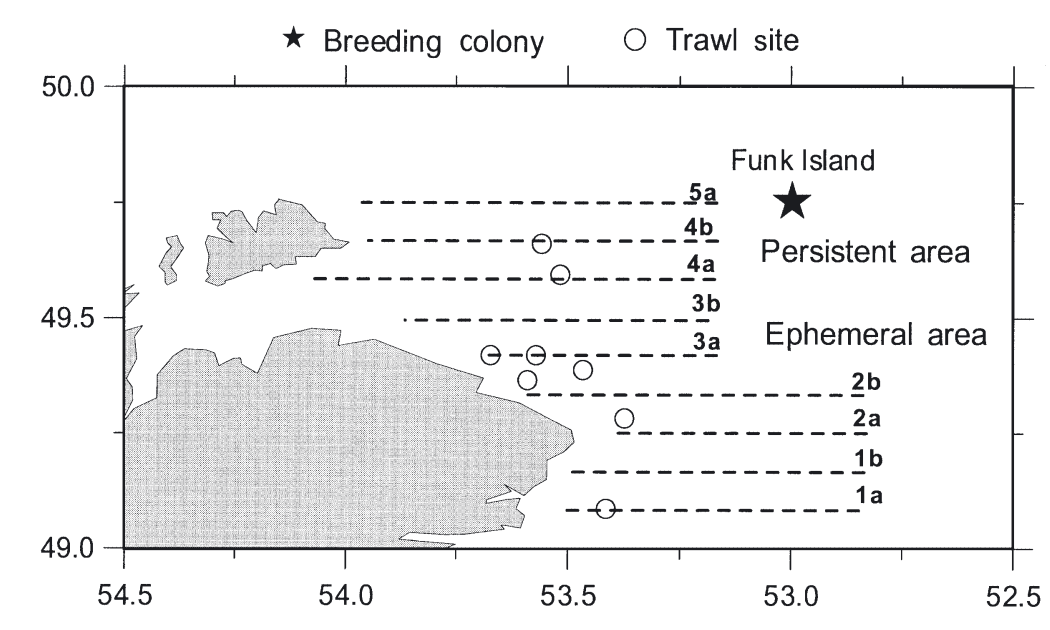

Fig. 1. Map of the study area, showing the 9 survey lines with identifying numbers (dashed line), the Funk Island colony of common murres Uria aalge (star) and trawling sites (circles) within the 2 foraging areas (persistent area: $4 \mathrm{a}, \mathrm{b}$; ephemeral area: 2a,b, 3a,b), defined in Davoren (2001) 
igational software package (Bioplot 1991, BioSonics, Version 2.0) continuously recorded the ship's position (cruise track) and Greenwich Mean Time (GMT) every minute. The date and GMT were used to merge the bird data with acoustic estimates and cruise track data into $1 \mathrm{~min}(\sim 250 \mathrm{~m})$ bins. Following this initial survey, the areas of high bird and prey abundance ('hot spots') defined in a previous paper (Davoren et al. in press) were revisited on 2 occasions during a 2 wk period. Upon revisit, an acoustic survey was conducted simultaneously with bird counts along the initial survey route.

Acoustic estimates. The distribution and relative abundance of prey in the water column were estimated using a Simrad EQ100 echo-sounding system that operated through a hull-mounted single-beam transducer with a frequency of $38 \mathrm{kHz}$. This frequency is appropriate for observations of fish targets and the distinct shape of capelin schools allows them to be separated from other fish species (e.g. American sand lance Ammodytes americanus, Atlantic herring Clupea harengus harengus) within the study area (O'Driscoll et al. 2000). The transducer had a $10^{\circ}$ beam angle and the echo sounder was operated at $1 \mathrm{ping} \mathrm{s}^{-1}$, a range of $150 \mathrm{~m}$ at $1 / 10$ power, and a bandwidth of $0.3 \mathrm{~ms}$. The transducer was at a depth of $3 \mathrm{~m}$ and beam pattern would not form within a range of $5 \mathrm{~m}$; therefore, acoustic signals were not reliable until $8 \mathrm{~m}$. The sample depth of the acoustic system (8 to $250 \mathrm{~m}$ ) and boat speed (14 to $16 \mathrm{~km} \mathrm{~h}^{-1}$ ) were held constant throughout the survey. Echograms were continuously printed during transects and GMT was marked on the echograms every $10 \mathrm{~min}$.

Following Piatt (1990), the relative abundance of fish was quantified by estimating the percent cover of the prey image in each $1 \mathrm{~min}(\sim 250 \mathrm{~m})$ horizontal bin by $10 \mathrm{~m}$ vertical bin on the echogram. An index of percent cover of prey in each bin was estimated from 0 (no prey) to 9 (near-saturation). These values were squared before analysis (0 to 81 ) to account for the non-linear change in sounder intensity relative to fish school density (Piatt 1990). This squared relative measure is hereafter referred to as the 'acoustic abundance score'. This technique allowed us to quantify the presence/absence of fish and relative abundance of fish and to evaluate the shape of fish schools, because a high-resolution echosounder with electronic datacapture capabilities was not available during the survey. At-sea observations, species composition of trawl sets, and shapes of acoustic schools on echograms were combined to classify the acoustic signals representing capelin schools. The initial survey and the revisit transects were each divided into a continuous series of $250 \times 300 \mathrm{~m}$ blocks, where the squared acoustic abundance score (scale: 0 to 81 ) was summed over the entire water column, from 0 to $50 \mathrm{~m}$ and from 51 to $250 \mathrm{~m}$. The water column was divided in this way to reflect the vertical distribution of the 2 types of capelin schools observed: persistent (51 to $250 \mathrm{~m}$ ) and ephemeral (0 to 50 m; Davoren 2001).

Seabird counts. During acoustic transects, seabirds were counted simultaneously using standard strip transect methods (Method Ib; Tasker et al. 1984). One observer made continuous counts of seabirds from the bridge out to $300 \mathrm{~m}$ in a $90^{\circ}$ arc from the tip of the bow to the port side of the vessel. Counts were entered directly into a laptop computer along with behavioural descriptions (on the water, feeding, flying and flight direction, flying with fish). The laptop was connected to the navigational system of the vessel and counting software (D. Senciall, Birds \& Beasty Counter 1998, Fisheries and Oceans Canada, Version 1.0) was used to append a position (latitude and longitude) and GMT to each bird entry.

Statistical analyses. The survey area was partitioned into 2 subareas (Persistent and Ephemeral Areas; Fig. 1). The persistent area consisted of Transects 4a and $b$ and the ephemeral area consisted of Transects $2 \mathrm{a}, \mathrm{b}, 3 \mathrm{a}$ and $\mathrm{b}$, with each $12 \mathrm{~h}$ day of survey (i.e. Transects 2, 3 and 4) treated separately. Transects conducted upon revisit to both subareas were also treated separately.

Univariate statistics based on the neighbour K statistic (Ripley 1981) were used to assess whether the distribution of murres and acoustic prey separately along each transect was significantly different from random at a number of spatial scales (see O'Driscoll 1998). This method is based on the distance between individuals along a transect and, thus, results are not influenced by a high proportion of zero counts (O'Driscoll 1998), as are other traditional time-series analyses, such as spectral analysis (e.g. Horne \& Schneider 1997) and geostatistical analyses (e.g. Begg \& Reid 1997). Only murres that were either feeding (i.e. diving) or assumed to be feeding (i.e. sitting on the water) were used in our analyses. For each transect, the test statistic, $\mathrm{E}[N(t)]$, was determined. $\mathrm{E}[N(t)]$ is the average number of murres or average prey abundance over all $250 \mathrm{~m}$ bins. This statistic was calculated at different spatial scales (t), following O'Driscoll (1998):

$$
\mathrm{E}[N(t)]=\sum_{\substack{i=1 \\ i \neq j}}^{N} \sum_{j=1}^{N} I_{t}\left(u_{i j} .\right.
$$

where $N$ is the total number of individuals observed in an area, $u_{i j}$ is the distance from individual $i$ to individual $j$ and $I_{t}\left(u_{i j}\right)$ is an indicator function, which is equal to 1 if $u_{i j}<t$ but equal to 0 otherwise. The spatial scales analyzed $(t)$ ranged from $250 \mathrm{~m}$ and increased at $250 \mathrm{~m}$ increments up to half the length of the transect 
in each subarea-the persistent area: Transect $4 \mathrm{a}, \mathrm{b}$ $(38 \mathrm{~km})$; the ephemeral area: Transect $3 a, b(42 \mathrm{~km})$ and Transect 2a,b $(25 \mathrm{~km})$. The average number of murres and average acoustic abundance score expected from a random distribution $(\mathrm{E}[N(t)]$ RAND) was calculated using Monte Carlo procedures (O'Driscoll 1998). We calculated the percentage of the $999 \mathrm{E}[N(t)]$ that were greater than, equal to or less than the $\mathrm{E}[N(t)]$ of the observed data (E[N(t)] OBS). If $\mathrm{E}[N(t)]$ OBS was greater than $95 \%$ of the $999 \mathrm{E}[N(t)]$, then birds or prey were determined to be significantly clustered. Alternately, if $\mathrm{E}[N(t)]$ OBS was equal to or less than the $95 \%$ of the $999 \mathrm{E}[N(t)]$, then birds or prey density were determined to be randomly or uniformly distributed, respectively. This was repeated at all spatial scales $(t)$ for each transect.

The average $\mathrm{E}[N(t)]$ of the 999 randomized realizations $(\mathrm{E}[N(t)]$ RAND) was calculated at each spatial scale within a transect. We subtracted $\mathrm{E}[N(t)]$ OBS from $\mathrm{E}[N(t)]$ RAND to determine $L(t)$, or the average number of 'extra' murres or 'extra' prey at each spatial scale. The scale of aggregation of murres and prey was defined by the spatial scale at which $L(t)$ for murres or prey was higher than the succeeding 3 values for a transect. This avoided identifying small jumps in values as peaks (O'Driscoll et al. 2000). A measure of the density of murres or prey per aggregation was determined by the value of $L(t)$ at the scale of aggregation ('crowding'). The distance between aggregations of murres and aggregations of prey was defined by the spatial scale at which $L(t)$ reached its maximum for a transect (O'Driscoll 1998).

Bivariate $\mathrm{K}$ analysis was used to determine whether there were significantly more murres associated with prey aggregations than would be expected if murres were distributed randomly within a transect (O'Driscoll 1998). For each transect, the observed $\mathrm{E}[N(t)]$ OBS and expected random distribution of murres $\mathrm{E}[N(t)]$ RAND at each spatial scale in relation to each prey aggregation in $250 \mathrm{~m}$ block increments was calculated, using 999 Monte Carlo simulations as above. The average number of 'extra' murres at each prey aggregation and each spatial scale, $L(t)$, was again calculated by subtracting $\mathrm{E}[N(t)]$ RAND from $\mathrm{E}[N(t)]$ OBS. The scale of maximum association, or 'tracking scale', of murres to prey was defined by the scale at which $L(t)$ of murres was first higher than the succeeding 3 values. The number of 'extra' murres associated with any given prey aggregation ('crowding') was determined by the value of $L(t)$ for murres at the scale of maximum association. Statistical significance was set at $\alpha=0.05$ and all averages are reported as $\pm 1 \mathrm{SE}$.

Habitat selection model. We explored habitat selection of murres flying out from Funk Island on a foraging trip to the persistent and ephemeral areas, based on the characteristics of the distribution of capelin abundance and qualities in relation to the colony within foraging ranges of murres from Funk Island (summarized in Table 1). Murres revisit prey aggregations much more often (daily) than we could during the survey ( 3 visits over $2 w_{k}$; Davoren 2001) and, therefore, we assumed that they have knowledge of these prey-patch conditions.

As a proxy of flying effort, we calculated the ratio of energy expended during flight $\left(R_{\mathrm{fly}}\right)$ to the ephemeral area relative to the persistent area based on the difference in distances to each foraging area $\left(R_{\mathrm{fly}}=\right.$ $60 \div 45 \mathrm{~km}=1.3$; Table 1 ). We assumed that energy expended per distance did not differ during flight to either area because both areas were a similar bearing from the colony and, thus, birds flying to either area would be affected similarly by wind direction and speed. As a proxy of diving effort, we calculated the ratio of energy consumed per dive in the ephemeral area relative to the persistent area based on the difference in energy density values between spent $(3.9 \mathrm{~kJ}$ $\left.\mathrm{g}^{-1}\right)$ and gravid capelin $\left(4.6 \mathrm{~kJ} \mathrm{~g}^{-1}\right.$; Montevecchi \& Piatt 1984) and based on the fact that murres collect no more than 1 fish per dive (Sanford \& Harris 1967, Swennen \& Duiven 1991; $R_{\text {dive }}=3.9 \div 4.6 \mathrm{~kJ} \mathrm{~g}^{-1}=0.8$ ). Therefore, for murres to recover the energetic costs of flying to the ephemeral area (1.3 times higher), as well as the lower prey quality ( 0.8 times lower), they would have to consume more energy in the ephemeral area $\left(R_{\text {recover }}=\right.$ $1.3 \div 0.8=1.6$ ). Based on these calculations murres should never fly past the persistent area to forage in the ephemeral area because they would have to increase foraging effort by 1.6 times to gain the same amount of energy as in the persistent area.

We explored one underlying mechanism that might render foraging effort equivalent in the 2 areas. Murre abundance was highly variable in both areas, suggesting that murres would not have complete knowledge of conspecific densities within either foraging area. We explored the importance and positive/negative (i.e. cooperative/competitive) influence of murre density on foraging effort of murres, by examining how frequently birds are found at various densities (Grunbaum \& Veit in press). The spatial scale at which densities of murres will influence foraging effort is likely around $250 \mathrm{~m}^{2}$, because murres were observed to move horizontally at this scale during underwater pursuit of prey and, thus, would interact at this scale during prey capture. We determined the frequency distribution of $250 \mathrm{~m}^{2}$ blocks that contained various densities of murres throughout both the initial and revisit surveys. We described the slope of the line from the log density versus log frequency plot to infer whether increasing murre densities would have a positive or negative impact on foraging effort and how this slope varied among days. 
Foraging efficiency of birds within flocks has been expressed as a powerlaw relationship:

$$
Q_{n}=n^{-m}
$$

where $Q_{n}$ is the foraging efficiency, or energy intake rate, of individuals with a flock of size $n$ and $m$ is the strength of interference (positive value) or facilitation (negative value) among birds within a flock (Kacelnik et al. 1992). We used the slope of the line from the log density versus log frequency plot to estimate values of $m$ in each foraging area. Using Eq. (1), we calculated $Q_{n}$ for each foraging area based on the estimates of $m$ and the range of observed murre densities per $250 \mathrm{~m}^{2}$.

We assumed that murres would act in an ideal free manner (Fretwell \& Lucas 1970), by sampling the persistent area on their outbound trip to determine current densities, at which point they would decide to stay in the persistent area or switch to the ephemeral area. We also assumed that the energetic cost of sampling the persistent area would be negligible relative to the costs of foraging in the ephemeral area if conditions were ideal in the persistent area (Grunbaum \& Veit in press). We calculated the ratio of foraging efficiency $\left(Q_{n}\right)$ in the persistent area relative to the ephemeral area by varying murre densities in the persistent area over the range of densities encountered, and comparing the resulting values to those arising from each observed density in the ephemeral area. We defined the 'switching density' at each density in the ephemeral area as the density in the persistent area at which the ratio of foraging efficiency fell below 1 (e.g. it became more profitable to forage in the ephemeral area). Given the variability in murre abundance within each foraging area, however, we assumed that a murre would not have knowledge of the densities in the ephemeral area but might retain knowledge of the densities normally encountered. Each density per $250 \mathrm{~m}^{2}$ in the ephemeral area had an associated probability of encounter based on the frequency distribution of densities encountered. We plotted the
Ephemeral area (July 20)
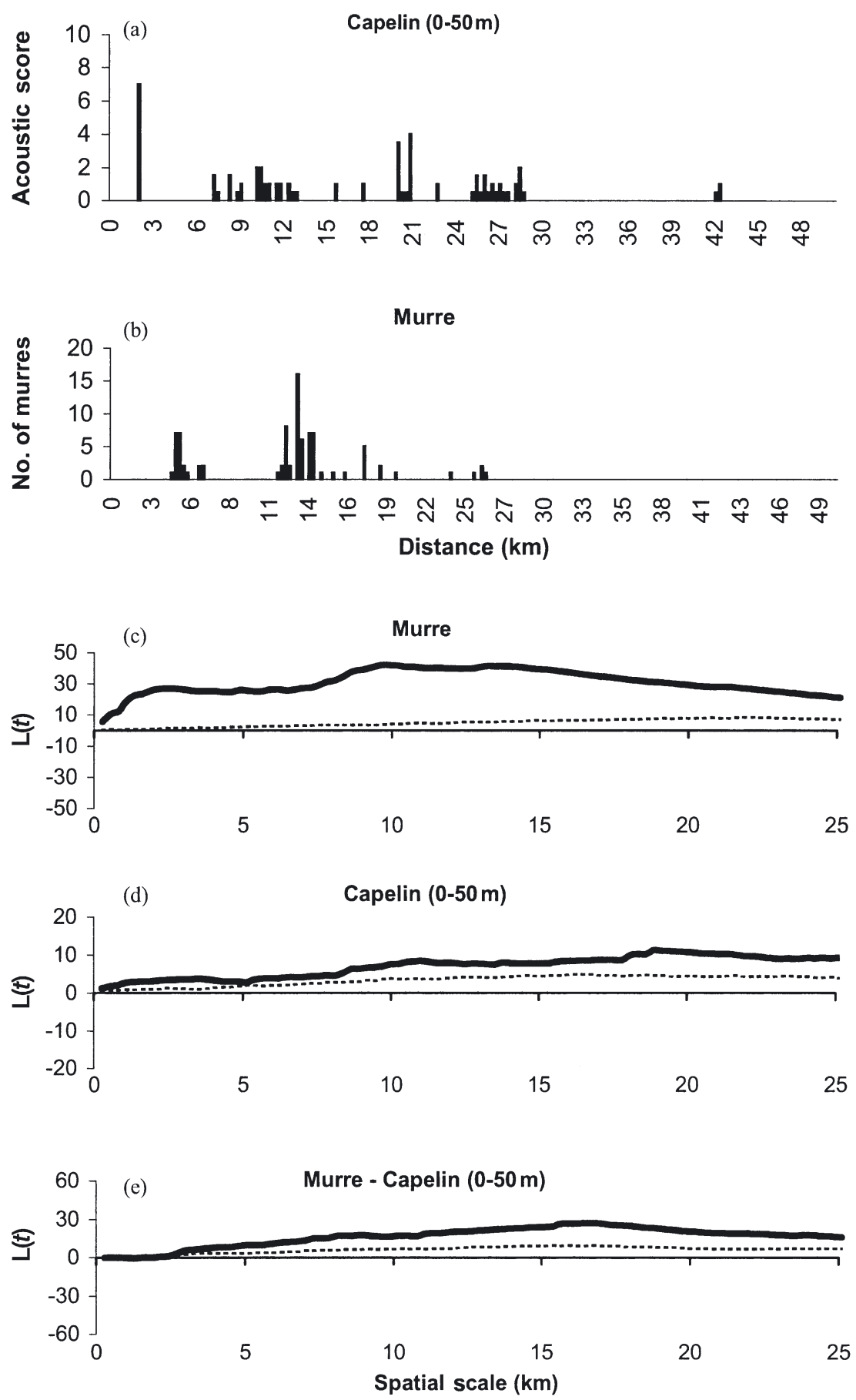

Fig. 2. Distribution of (a) capelin Mallotus villosus and (b) common murre Uria aalge along transects, and univariate plots of the number of 'extra' neighbours, $L(t)$, against the spatial scale of analysis for (c) murres and (d) capelin at specific depths along with (e) the bivariate plots of the number of 'extra' murre neighbours, $L(t)$, to capelin schools against the spatial scale of analysis in the 2 main foraging areas of common murres: the persistent area (July 21) and the ephemeral area (July 20). In univariate (c,d) and bivariate (e) plots the bold line represents the number of 'extra' neighbours and the thin line represents the upper $95 \%$ confidence limit 
Persistent area (Julv 21)
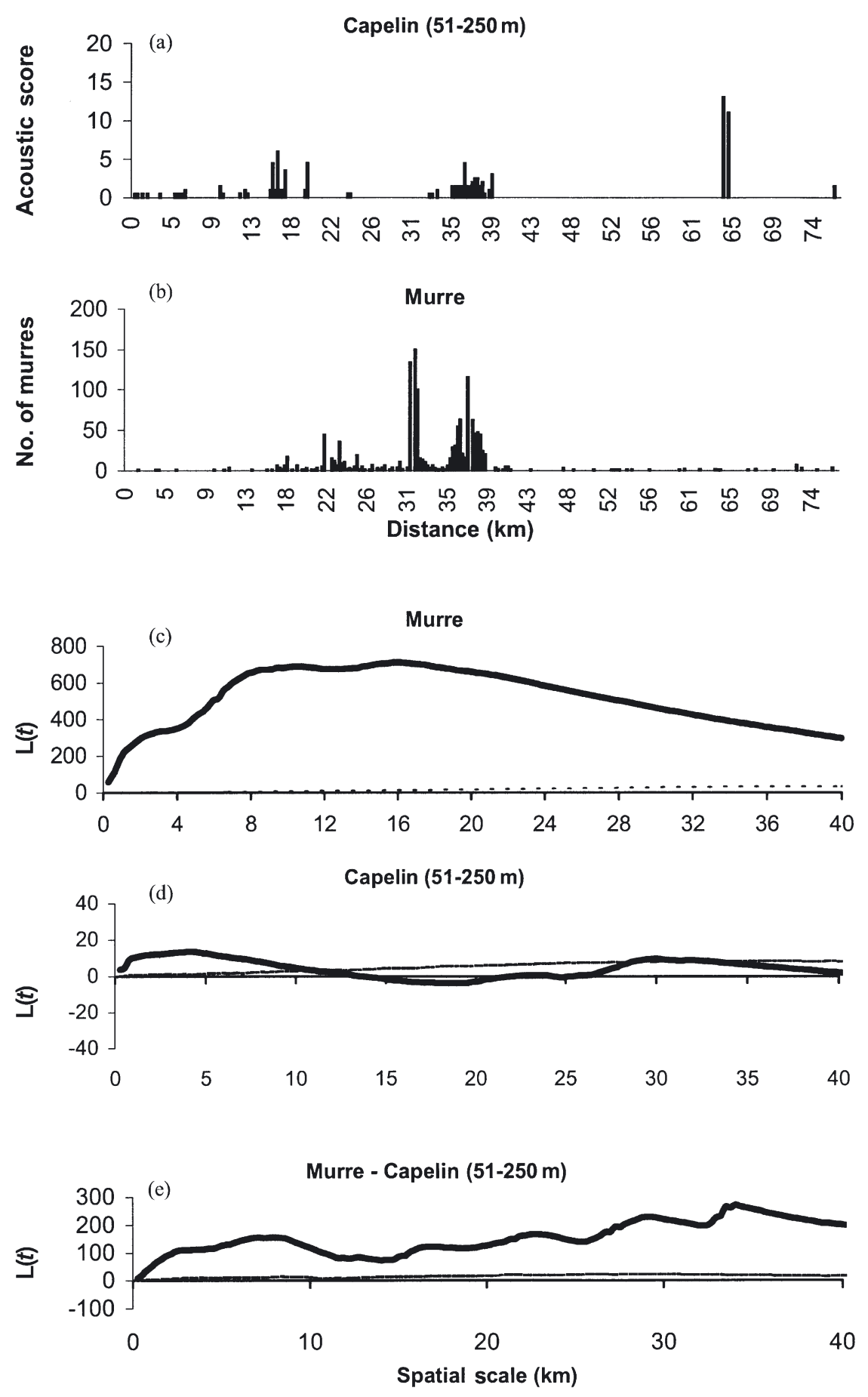

Fig. 2 (continued)

cumulative probability of encountering a particular murre density in the ephemeral area against the switching density in the persistent area, allowing us to describe the probability that a murre foraging at a particular density in the persistent area would increase its foraging efficiency by switching to the ephemeral area.

\section{RESULTS}

\section{Capelin characteristics}

During the initial survey, capelin was significantly clustered $(L(t)>0)$ at most small to moderate spatial scales, but at larger spatial scales $(10$ to $40 \mathrm{~km})$ capelin distribution generally became uniform $(L(t)<0$; Fig. 2$)$. The average acoustic abundance score (crowding) of capelin was low at small spatial scales and increased up to the aggregation scale, after which it declined. The aggregation scale of capelin varied from 1.0 to $2.4 \mathrm{~km}$, but was similar in both areas at different depths (Table 2). The distance between capelin aggregations was generally larger in the ephemeral area relative to the persistent area but this was not statistically significant (Table 2). The average acoustic abundance score of capelin (crowding) at the depth range of 51 to $250 \mathrm{~m}$ was significantly higher in the persistent area compared to the ephemeral area (Table 2). In addition, crowding of capelin at the depth range of 51 to $250 \mathrm{~m}$ was significantly higher in the persistent area compared to that at the 0 to $51 \mathrm{~m}$ depth range in the ephemeral area $\left(t_{5}=11.77, \mathrm{p}=0.001\right.$; Table 2). This corresponds to the higher density of fish in deeper persistent schools compared to ephemeral schools that were higher in the water column (Davoren 2001).

\section{Bird characteristics}

During the initial survey, 14652 birds were observed in $800 \mathrm{~km}$ of transect, giving a sighting frequency of 17 birds $\mathrm{km}^{-1}$. The majority of the birds sighted were common murres $(85 \%, \mathrm{n}=12387)$. Murres were significantly clustered $(L(t)>0)$ at all spatial scales, but tended towards a more uniform distribution at small spatial scales (Fig. 2). The average number of murres (crowding) was low at small spatial scales (at $250 \mathrm{~m}^{2}$ : persistent area, 29; ephemeral area, 3 to 6 ; Fig. 2), increased up to the scale of aggregation, and then declined (Fig. 2). The aggregation scale for murres was similar in both areas, but the crowding of murres was significantly higher in the persistent area compared to the ephemeral area (Table 2). The distance between murre aggregations was similar in both areas. 
Table 2. Mean \pm SE of the spatial scale of aggregation of common murre Uria aalge and capelin Mallotus villosus, the extent of crowding (see subsection 'Statistical analyses' for explanation) within these aggregations, the distances between these aggregations, and the tracking scale of murres to capelin within the persistent area (July 21, 22, 23, 24) and ephemeral area (July 19, 20, $25,27)$ during the initial survey and all revisit surveys. The df for all $t$-tests is 5

\begin{tabular}{|c|c|c|c|c|c|c|c|c|}
\hline \multirow[t]{2}{*}{ Category } & \multicolumn{2}{|c|}{ Persistent area } & \multicolumn{2}{|c|}{ Ephemeral area } & \multicolumn{2}{|r|}{$t$} & \multicolumn{2}{|c|}{$\mathrm{p}$} \\
\hline & Scale $(\mathrm{km})$ & Crowding & Scale $(\mathrm{km})$ & Crowding & (Scale) & (Crowd) & (Scale) & (Crowd) \\
\hline \multicolumn{9}{|l|}{ Aggregation scale } \\
\hline Murre & $4.4 \pm 0.1$ & $479.7 \pm 103.4$ & $5.1 \pm 0.3$ & $38.3 \pm 11.1$ & 2.19 & 4.25 & 0.116 & 0.051 \\
\hline Capelin: 0-50 m & $1.5 \pm 0.3$ & $2.7 \pm 0.4$ & $1.8 \pm 0.3$ & $3.7 \pm 0.4$ & 0.57 & 1.58 & 0.625 & 0.254 \\
\hline Capelin: $51-250 \mathrm{~m}$ & $1.1 \pm 0.3$ & $15.3 \pm 0.9$ & $1.2 \pm 0.5$ & $2.7 \pm 0.9$ & 0.27 & 10.00 & 0.800 & 0.0002 \\
\hline \multicolumn{9}{|l|}{ Distance between aggregations } \\
\hline Murre & $9.0 \pm 3.3$ & & $7.6 \pm 1.4$ & & 0.39 & & 0.725 & \\
\hline Capelin: 0-50 m & $3.3 \pm 0.2$ & & $9.3 \pm 3.8$ & & 1.57 & & 0.214 & \\
\hline Capelin: $51-250 \mathrm{~m}$ & $3.7 \pm 1.7$ & & $6.9 \pm 3.3$ & & 0.86 & & 0.439 & \\
\hline \multicolumn{9}{|l|}{ Tracking scale } \\
\hline Murre and Capelin 0-50 m & $7.2 \pm 0.9$ & $150.1 \pm 43.8$ & $1.2 \pm 0.2$ & $34.3 \pm 15.3$ & 6.80 & 2.50 & 0.021 & 0.130 \\
\hline Murre and Capelin 51-250 m & $2.6 \pm 0.4$ & $320.0 \pm 108.4$ & $35.6 \pm 10.5$ & $25.3 \pm 15.0$ & 3.14 & 2.69 & 0.052 & 0.115 \\
\hline
\end{tabular}

During the initial survey, murres sitting on the water were patchily distributed at the scale of the survey (meso-scale; Fig. 2), with $77 \%$ of the total number of $250 \mathrm{~m}^{2}$ blocks surveyed containing no murres (Table 3 ). Many of the non-zero $250 \mathrm{~m}$ blocks during the initial survey contained a single sitting murre (40\%, Table 3$)$, suggesting that murres tended to forage alone. Mixedspecies feeding assemblages, as described by Hoffman et al. (1981), were never observed in the survey area but rather murres tended to aggregate loosely within foraging areas. The distribution of flock sizes, however, varied among the ephemeral and persistent areas, with $95 \%$ of the $250 \mathrm{~m}^{2}$ blocks in the ephemeral area having lower densities ( 5 to 42 per $250 \mathrm{~m}^{2}$ ) than in the persistent area (19 to 107 per $250 \mathrm{~m}^{2}$; Table 3). The mean and median densities per $250 \mathrm{~m}^{2}$ and variability around the mean (SE) also were higher in the persistent relative to the ephemeral area, but there was consistently a modal density of 2 murres per $250 \mathrm{~m}^{2}$ during all surveys in both areas (Table 3). Summary statistics varied among visits in both areas, but reflected these general trends.

\section{Murre-capelin interaction}

In both areas, murres were significantly clustered with capelin at most spatial scales (Fig. 2). In the

Table 3. Uria aalge. Summary statistics of the number of common murres per $250 \mathrm{~m}^{2}$, estimates of the interference $(\mathrm{m})$ among murres within $250 \mathrm{~m}^{2}$ blocks, the percentage of $250 \mathrm{~m}^{2}$ blocks with no murres out of the total number of $250 \mathrm{~m}^{2}$ blocks and the percentage of $250 \mathrm{~m}^{2}$ blocks with $1,<5$, and $>50$ murres per $250 \mathrm{~m}^{2}$ out of the total number of non-zero $250 \mathrm{~m}^{2}$ blocks within the persistent (July 21, 22, 23, 24) and ephemeral areas (July 19, 20, 25, 27) throughout the study period (July 18-28)

\begin{tabular}{|c|c|c|c|c|c|c|c|c|}
\hline \multirow{2}{*}{$\begin{array}{l}\text { Summary statistics } \\
\left(\text { per } 250 \mathrm{~m}^{2}\right)\end{array}$} & \multicolumn{4}{|c|}{ Ephemeral area } & \multicolumn{4}{|c|}{ - Persistent area } \\
\hline & $\begin{array}{l}\text { Initial and } \\
\text { revisits }\end{array}$ & Initial & 2nd visit & 3rd visit & $\begin{array}{l}\text { Initial and } \\
\text { revisits }\end{array}$ & Initial & 2nd visit & 3rd visit \\
\hline Mode & 2 & 2 & 2 & 2 & 2 & 2 & 2 & 2 \\
\hline Median & 4 & 4 & 5 & 3 & 6 & 6 & 13 & 3 \\
\hline Mean & 9.0 & 9.0 & 10.5 & 3.1 & 19.6 & 16.9 & 31.9 & 8.0 \\
\hline SE & 0.7 & 1.0 & 1.6 & 0.3 & 2.7 & 3.1 & 7.1 & 1.8 \\
\hline Maximum & 83 & 55 & 83 & 8 & 300 & 150 & 300 & 44 \\
\hline $\begin{array}{l}\text { Slope of the log frequency } \\
\text { versus log density plot }(m)\end{array}$ & 1.2 & 1.1 & 0.8 & 1.6 & 0.8 & 0.7 & 0.3 & 0.8 \\
\hline Total no. $250 \mathrm{~m}$ blocks & 1519 & 1082 & 263 & 174 & 965 & 505 & 233 & 227 \\
\hline Percentages of $250 \mathrm{~m}$ blocks & & & & & & & & \\
\hline No. murres $=0$ (total) & 72 & 75 & 55 & 77 & 73 & 73 & 75 & 71 \\
\hline No. murres = 1 (non-zero) & 40 & 44 & 49 & 50 & 36 & 38 & 16 & 51 \\
\hline No. murres < 5 (non-zero) & 80 & 81 & 70 & 98 & 64 & 66 & 38 & 85 \\
\hline No. murres > 50 (non-zero) & 1 & 1 & 3 & 0 & 7 & 5 & 17 & 0 \\
\hline
\end{tabular}




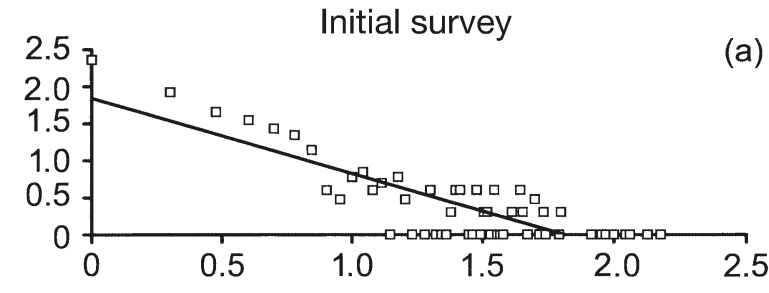

Ephemeral area (initial and revisit surveys)

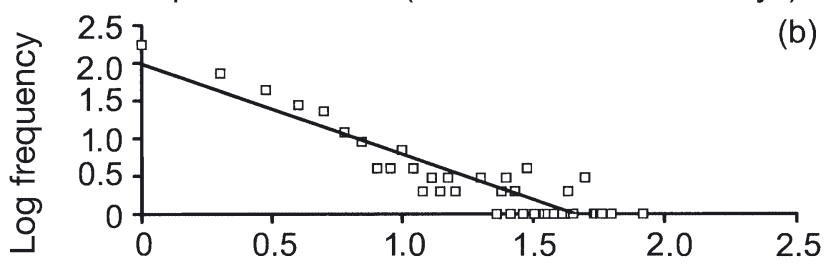

Persistent area (initial and revisit surveys)

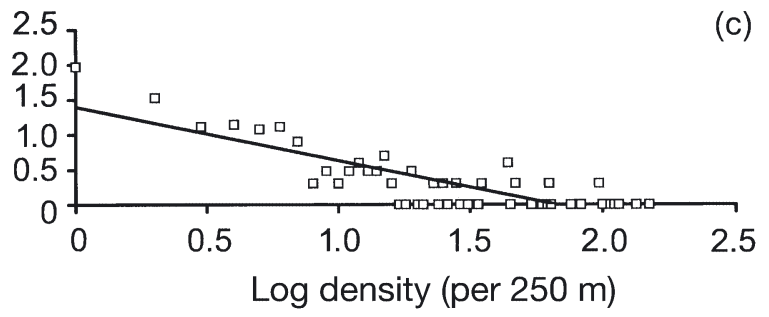

Fig. 3. Uria aalge. Log density of common murres per $250 \mathrm{~m}^{2}$ versus the log frequency of densities encountered during the (a) initial survey, (b) initial and revisit surveys in the ephemeral area and (c) initial and revisit surveys in the persistent area scores, while isolated patches with high scores were often not used (Fig. 2).

Murres always had higher aggregation scales than the types of capelin schools they were tracking (Table 2). The crowding of murres at capelin aggregations generally was higher in the persistent area compared to the ephemeral area, but this was not statistically significant, owing to the large variation in crowding values (Table 2).

\section{Habitat selection model}

Slopes of the log density versus log frequency plots for murres during the initial survey and revisit transects were always negative, suggesting that there was interference among murres in the study area (Fig. 3). Generally, interference in the ephemeral area appeared to be stronger than in the persistent area, although there was high variability among transects (Table 3). Through our model, we found a characteristic switching density in the persistent area (foraging efficiency ratio <1) up to a density of 40 murres per $250 \mathrm{~m}^{2}$ in the ephemeral area, above which it is always better for a murre to stay in the persistent area (Fig. 4). We plotted the percent chance of encountering a particular murre density in the ephemeral area against the switching density in the persistent area to describe the probability that murres would increase their foraging efficiency by switching to the ephemeral area at a particular density in the persistent area (Fig. 5). Overall, at ephemeral area, the tracking scale of murres to capelin schools was significantly smaller for schools within 0 to $50 \mathrm{~m}$ compared to those within 51 to $250 \mathrm{~m}\left(t_{6}=3.27\right.$, $p=0.047$ ), suggesting that they preferentially tracked ephemeral capelin schools off the seabed (Table 2). In the persistent area, the tracking scale of murres to capelin schools was significantly smaller for schools within 51 to $250 \mathrm{~m}\left(t_{4}=4.92, \mathrm{p}=\right.$ $0.016)$, suggesting that they preferentially tracked persistent capelin schools associated with the seabed (Table 2). Murres preferentially tracking ephemeral capelin schools in the ephemeral area had significantly smaller tracking scales compared to murres tracking persistent capelin schools in the persistent area $\left(t_{5}=3.18, \mathrm{p}=\right.$ 0.050; Table 2). In addition, there was a tendency for schools with low acoustic abundance scores to be used by murres if they were close to patches with high

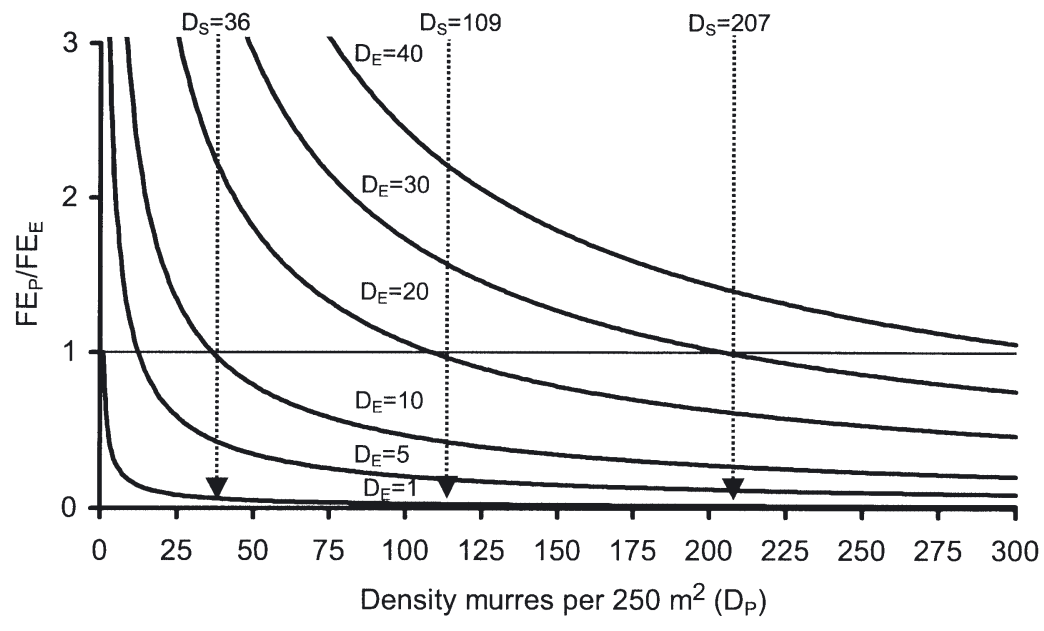

Fig. 4. Uria aalge. Ratio of foraging efficiency $\left(Q_{n}\right)$ in the persistent relative to the ephemeral area $\left(\mathrm{FE}_{\mathrm{P}} / \mathrm{FE}_{\mathrm{E}}\right)$ at varying densities of common murres per $250 \mathrm{~m}^{2}$ in the persistent area $\left(D_{\mathrm{P}}\right)$, while density in the ephemeral area $\left(D_{\mathrm{E}}\right)$ is held constant at $1,5,10,20,30$ and 40 murres per $250 \mathrm{~m}^{2}$. Arrows indicate the 'switching density' $\left(D_{\mathrm{S}}\right)$ at $D_{\mathrm{E}}=10,20,30$. Switching density is the density of murres per $250 \mathrm{~m}^{2}$ in the persistent area $\left(D_{\mathrm{P}}\right)$ where foraging efficiency would be increased if murres switched from the persistent area to the ephemeral area 


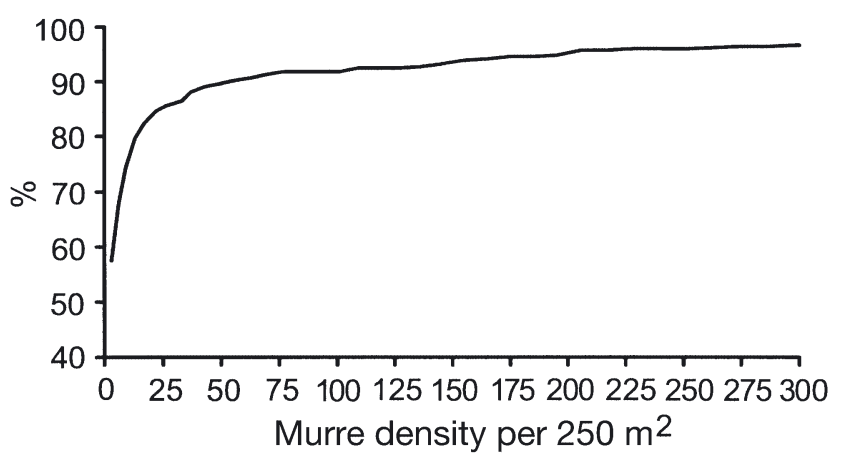

Fig. 5. Uria aalge. Percent chance of a common murre increasing its foraging efficiency $\left(Q_{n}\right)$ by switching from the persistent area to the ephemeral area at a particular density of murres per $250 \mathrm{~m}^{2}$ in the persistent area $\left(D_{\mathrm{P}}\right)$

densities $>50$ murres per $250 \mathrm{~m}^{2}$ in the persistent area, a murre would have a $>90 \%$ chance of encountering flock sizes in the ephemeral area that would allow it to forage more efficiently than in the persistent area.

\section{DISCUSSION}

As found in this study, seabirds at sea are generally patchily distributed with a high proportion of birds encountered in a few large, dense prey aggregations, while smaller or more dispersed prey aggregations were under used (Heinemann et al. 1989, Hunt et al. 1991, Veit et al. 1993). This suggests that at large spatial scales, seabirds generally concentrate their foraging efforts in areas where prey aggregations are predictable and highly abundant ('hot spots') and, thus, possibly avoid energetically costly search activities (Cairns \& Schneider 1990, Hunt \& Harrison 1990, Davoren et al. in press). In support, many researchers have found large aggregations of seabirds at temporally and spatially persistent prey aggregations and have suggested that these predictable aggregations might be important to increase foraging efficiency in marine birds (Schneider et al. 1987, Coyle et al. 1992, Decker \& Hunt 1996, Davoren et al. in press), especially during breeding when metabolic demands are highest (Drent \& Daan 1980). Murres appeared to maximize encounter rates with their prey, thereby maximizing their net energetic benefit (Horne \& Schneider 1994), as evidenced by larger murre aggregations than those of capelin, and tracking scales of murres to capelin that were at similar or smaller spatial scales than the aggregation scales of capelin. Tighter associations among murre and capelin aggregations were found in the ephemeral area $(1.2 \pm 0.2 \mathrm{~km})$ relative to the persistent area $(2.6 \pm 0.4 \mathrm{~km})$. Differences in the scale of association of murres and capelin in the 2 areas might reflect different foraging strategies in each area due to the persistent versus ephemeral behaviour of capelin schools.

Distribution patterns at the scale of the foraging range (meso-scale: 1 to $100 \mathrm{~km}$ ) revealed that murres were highly clustered, being found in $25 \%$ of the surveyed area within 2 main foraging areas. Murres tended to distribute themselves according to the central-place foraging model and the ideal free distribution (IFD) at this spatial scale, with fewer murres found in the low-quality, ephemeral area farther from the colony relative to the high-quality, persistent area closer to the colony. At fine spatial scales $\left(250 \mathrm{~m}^{2}\right)$ within foraging areas, murres tended towards a more uniform distribution, as has been observed in other studies (e.g. Logerwell et al. 1998), and tended to be found at lower densities (mode: 2 murres per $250 \mathrm{~m}^{2}$ ). Interference competition rather than cooperative facilitation was inferred from the frequency distribution of murre densities per $250 \mathrm{~m}^{2}$ over the study area, with higher levels of interference occurring within the ephemeral area relative to the persistent area. Modeling revealed that at densities $>50$ murres per $250 \mathrm{~m}^{2}$ in the persistent area, murres would have a $>90 \%$ chance of encountering flock sizes in the ephemeral area that would allow them to increase foraging efficiency relative to the persistent area. Distribution patterns, however, revealed that $7 \%$ of $250 \mathrm{~m}^{2}$ blocks within the persistent area had >50 murres. Overall, differences in the level of clustering of murres at coarse and fine spatial scales suggests that cooperative foraging may be important in locating prey on coarse-scales, or murres may simply aggregate in areas of high prey abundance, but competitive interactions may become important on fine-scales during prey capture (Logerwell et al. 1998).

\section{Predator-prey interactions}

Murres tracked capelin at smaller spatial scales in the ephemeral area than in the persistent area. Murres foraging on the ephemeral capelin schools up in the water column presumably need to maintain close contact with schools between bouts of foraging during a foraging trip to avoid expending energy searching for prey if schools disperse between bouts. The smaller tracking scales of murres to capelin in the ephemeral area also may reflect an urgency to exploit ephemeral schools quickly before they escape predators between dives in a foraging bout (Ydenberg \& Forbes 1988). The presumably shorter dive durations due to the closer proximity of capelin to the ocean's surface would allow shorter recovery periods at the surface between 
dives (Ydenberg \& Clark 1989), resulting in murres maintaining close contact with schools of capelin among dives.

If murres forage on the basis of past experience and do not regularly sample their foraging environment, they would likely have knowledge of the locations of persistent schools of capelin in the persistent area but not of other capelin schools moving through the area. Therefore, tight associations with capelin would be expected only with persistent schools but not necessarily all schools in the area, resulting in perceptual constraints and, ultimately, into our measurement of larger tracking scales of murres to capelin. In addition, murres in the ephemeral area must presumably sample to a larger extent to locate capelin schools because they could not be predictably located. Sampling, either directly by diving or indirectly by local enhancement (Wittenberger \& Hunt 1985, Grunbaum \& Veit in press), would allow more current information on the locations and qualities of prey schools, resulting in smaller spatial scales of association between predators and prey relative to using memory.

Even though capelin aggregations were more dispersed in the ephemeral area, the distances among aggregations of murres were similar in both areas, suggesting that murres attempted to maintain visual contact in the ephemeral area despite low densities of murres. In addition, murres tended to concentrate at capelin aggregations with low abundance scores if they were close to high abundance aggregations, while isolated capelin aggregations with high abundance scores were ignored (Fig. 2). These distribution patterns are consistent with the use of indirect sampling strategies, such as local enhancement and network foraging, or a direct strategy, such as arearestricted search, to locate ephemeral prey schools at sea (Veit et al. 1993, Grunbaum \& Veit in press). The use of indirect techniques to reduce the energetic costs of searching for prey in the ephemeral area may have been important due to the smaller aggregation scales of capelin and the larger distances between aggregations compared to the persistent area.

\section{Conspecific interactions}

Despite the importance of cueing to the activities of conspecifics to reduce search costs for capelin, there is likely a trade-off between increased prey encounter rates due to social foraging interactions during prey search, and decreased prey consumption rates due to competitive interactions during prey capture. At fine spatial scales, competitive interactions among murres in this study appeared to be important, based on the frequency distributions of murre density per $250 \mathrm{~m}^{2}$, and appeared to be more important in the ephemeral relative to the persistent area. The divergent behaviour of capelin schools within each foraging area likely contributed to this difference. In the ephemeral area, capelin schools were highly mobile, off the seabed and could escape between successive dives (e.g. Hoffman et al. 1981, Ydenberg \& Forbes 1988, Ydenberg \& Clark 1989), suggesting that cooperative foraging, such as herding prey (Angell \& Balcomb 1982), and social foraging, such as local enhancement (Wittenburger \& Hunt 1985) could have been important in increasing the foraging efficiency of individuals. Individual benefits of higher conspecific densities during cooperative foraging have been shown to increase up to a threshold density, after which they decrease (e.g. Gotmark et al. 1986), suggesting that there is an 'optimal' density for cooperative foraging interactions. In contrast, in the persistent area, capelin schools were trapped against the seabed and, thus, there was presumably little benefit of cooperative foraging. Overall, the persistent area could likely support higher densities of murres due to the lack of cooperative foraging and to the higher mean densities of capelin schools in the persistent relative to the ephemeral schools and, thus, conspecific densities would only become a problem when densities were high enough to result in unavoidable interactions, such as collisions, during dives.

What might explain the remarkably high densities observed in the persistent area (e.g. 300 murres per $250 \mathrm{~m}^{2}$ )? Murres may lack complete knowledge of all the characteristics within these foraging areas (e.g. competitor densities) or may vary their selection criteria for a foraging area at temporal scales shorter than a foraging trip. For instance, if murres sample a number of areas on a foraging trip (e.g. trapline foraging pattern; Wanless et al. 1990, Benvenuti et al. 1998), densities of foraging birds would be less than those recorded during the survey (foraging and sampling). It is also possible that murres forage for themselves in the ephemeral area when competitor densities are sufficiently high in the persistent area, but may always capture a capelin for its chick in the persistent area on its return trip to the colony. This would reduce flight times carrying additional weight, thereby reducing energy expenditure during the return trip, and would also supply the chick with higher-quality prey (mature capelin) compared to those collected at the ephemeral area (spent capelin; Montevecchi \& Piatt 1984). Alternately, individuals could consistently only visit one area regardless of relative foraging or competitor conditions (perseveration; Pinel 1997). Individuals likely differ in how they integrate past experience with current knowledge, resulting in some individuals relying solely on past experience and, thus, in distributional 
patterns that do not conform to those predicted by models where individual variability is assumed to be minimal. In addition, approximately $30 \%$ of the seabird population around a colony during breeding is comprised of non-breeding birds (Montevecchi 2000). Non-breeders do not act as central-place foragers and, thus, may use different criteria from breeders when selecting a foraging area. Without knowledge of individual-based foraging behaviour (e.g. Benvenuti et al. 1998, Irons 1998), we can only speculate about the foraging patterns of these birds.

\section{Habitat selection theory}

Overall, the integration of many behavioural theories is necessary to fully understand foraging habitat selection. For instance, the central place foraging model predicts that murres should always choose the closest foraging area to the colony (Orians \& Pearson 1979). Incorporating this with the concept of fine-scale intraspecific interference under the framework of the IFD theory (Sutherland 1983) provided an explanation for why murres in this study appeared to select an area with lower-quality prey conditions. The IFD appeared to work qualitatively at large temporal and spatial scales but became unrealistic at smaller scales, possibly due to the complex integration of many foraging habitat characteristics, lack of knowledge of all characteristics or fixed behavioural patterns. Nevertheless, the IFD proved to be an important theoretical framework allowing the development of energetic models to explore the behavioural mechanisms that underlie spatial distribution patterns of murres. The integration of other variables important in habitat selection decisions, such as current energetic state and the variance as well as the mean competitor and prey densities (risk sensitive foraging theory; Caraco et al. 1980), will also be important in developing future models. The integration of all such theories will aid in generating ecosystem approaches to marine conservation.

\section{Summary}

The importance of competitive interactions in regulating breeding populations of seabirds has been debated rigorously in the literature (Ashmole 1963, Furness \& Birkhead 1984, Cairns 1989, Lewis et al. 2001). To date, however, few studies have quantified competitive interactions among foraging seabirds (Gotmark et al. 1986, Maniscalco et al. 2001, Grunbaum \& Veit in press), likely due to the difficulties in studying foraging behaviour of seabirds at sea. Large colony size has been related to reduced breeding suc- cess (Gaston et al. 1983, Hunt et al. 1986) and longer foraging trip duration (Lewis et al. 2001); however, the mechanisms responsible for such phenomena continue to be hard to directly observe and measure (Grunbaum $\&$ Veit in press). Even though models may not always be quantitatively accurate, depending on the appropriateness of the assumptions, they serve as important heuristic tools that allow researchers to generate hypotheses. It is becoming increasingly important, however, to directly test models by quantifying competitive interactions among seabirds foraging at sea. We suggest the necessity of integrating a variety of observational techniques to determine individual-level foraging patterns (e.g. telemetry and data logging devices) and distribution patterns of both seabirds and their prey (e.g. hydroacoustics). These techniques should be combined with observations that quantify individual consumption rates (e.g. internal stomach temperature loggers, Garthe et al. 2000) at different locations where foraging conditions are known. Through the creative integration of these observational techniques, researchers might resolve the relative importance of concentrations of conspecifics within foraging areas as a positive (local enhancement, Grunbaum \& Veit in press) or negative (intraspecific competition; Lewis et al. 2001) influence on seabird populations. This will be a productive avenue of future research and will likely influence the way researchers think about seabird population dynamics. The success of future studies certainly relies on the inclusion of multiple spatial and temporal scales and on the reevaluation of early ecological principles (e.g. Allee 1931).

Overall, we showed that divergent fine-scale behaviour of prey results in different scale associations of marine predators and prey, as well as varying mesoscale distribution patterns. Forage species, such as capelin, lie at the core of complex marine food webs, providing essential linkages among trophic levels. High-density aggregations of forage species, or hot spots, allow efficient energy transfer among trophic levels by maximizing predator-prey encounter rates, while minimizing the search efforts of predators for prey. Conservation of these hot spots is essential to maintain the integrity and stability of complex marine food webs and, thus, they are critical areas for protection.

Acknowledgements. We gratefully acknowledge Arnold Murphy for directing, operating and managing all technical equipment and electronic data aboard the RV 'Shamook' and for his insightful technical and scientific support. We thank Chantelle Burke, Eugene MacDonald and the crew of the Fisheries Canada RV 'Shamook' for assistance with field work. We thank Richard O'Driscoll for providing Matlab ${ }^{\odot}$ 
routines for spatial scale analyses. Special thanks to Brad de Young and David Schneider for help with developing models and for careful early reviews of this manuscript. Thanks also to Dave Sencial for providing bird counting software. Funding was provided by NSERC post-graduate scholarship to G.K.D., NSERC Operating Grant to W.A.M., DFO vessel support to J.T.A., Mountain Equipment Co-op, Royal Bank Marine Studies Fund, The National Chapter of Canada IODE, Orville Erickson Memorial Fund and Canadian Federation of Uni-versity Women.

\section{LITERATURE CITED}

Allee WC (1931) Animal aggregations: a study in general sociobiology. University of Chicago Press, Chicago

Angell T, Balcomb KC (1982) Marine birds and mammals of Puget Sound. Washington Sea Grant Program, Seattle

Ashmole NP (1963) The regulation of numbers of tropical oceanic birds. Ibis 103:458-473

Begg GS, Reid JB (1997) Spatial variation in seabird density at a shallow sea tidal mixing front in the Irish Sea. ICES J Mar Sci 54:552-565

Benvenuti S, Bonadonna F, Dall'Antonia LGGA (1998) Foraging flights of breeding thick-billed murres (Uria lomvia) as revealed by bird-borne direction recorders. Auk 115:57-66

Birt VL, Birt TP, Goulet D, Cairns DK, Montevecchi WA (1987) Ashmole's halo: direct evidence for prey depletion by a seabird. Mar Ecol Prog Ser 40:205-208

Cairns DK (1989) The regulation of seabird colony size: a hinterland model. Am Nat 134:141-146

Cairns DK, Schneider DC (1990) Hot spots in cold water: feeding habitat selection by thick-billed murres. Stud Avian Biol 14:52-60

Cairns DK, Bredin KA, Montevecchi WA (1987) Acitivity budgets and foraging ranges of breeding common murres. Auk 104:218-224

Cairns DK, Montevecchi WA, Threlfall W (1989) Researcher's Guide to Newfoundland Seabird Colonies. Memorial U Nfld Occas Pap Biol No 14, St. John's, Newfoundland and Labrador, p 1-34

Caraco T, Martindales S, Whittan TS (1980) An empirical demonstration of risk-sensitive foraging preferences. Anim Behav 28:820-830

Coyle KO, Hunt GL Jr, Decker MB, Weingartner TJ (1992) Murre foraging, epibenthic sound scattering and tidal advection over a shoal near St George's Island. Mar Ecol Prog Ser 83:1-14

Cresswell W (1997) Interference competition at low competitor densities in blackbirds Turdus merula. J Anim Ecol 66:461-471

Croy MI, Hughes RN (1991) The role of learning and memory in the feeding behaviour of the fifteen-spined stickleback Spinachia spinachia. Anim Behav 41:149-159

Davoren GK (2001) Predator-prey interactions of common murres (Uria aalge) and fish in the Northwest Atlantic: foraging strategies on multiple scales. PhD thesis, Memorial University of Newfoundland, St. John's

Davoren GK, Montevecchi WA (2003) Consequences of foraging trip duration on provisioning behaviour and fledging condition of common murres. J Avian Biol 34:44-53

Davoren GK, Montevecchi WA, Anderson JT (2002) Scaledependent associations of predators and prey: constraints imposed by flightlessness of common murres. Mar Ecol Prog Ser 245:259-272

Davoren GK, Montevecchi WA, Anderson JT (in press) Search strategies of a pursuit-diving marine bird and the persistence of prey patches. Ecology

Decker MB, Hunt GL Jr (1996) Foraging by murres (Uria spp.) at tidal fronts surrounding the Pribilof Islands, Alaska, USA. Mar Ecol Prog Ser 139:1-10

Drent RH, Daan S (1980) The prudent parent: energetic adjustments in avian breeding. Ardea 68:225-252

Fretwell SD, Lucas JH Jr (1970) On territorial behaviour and other factors influencing habitat distribution in birds. Acta Biotheor 19:16-36

Furness RW, Birkhead TR (1984) Seabird colony distributions suggest competition for food supplies during the breeding season. Nature 311:655-656

Garthe S, Benvenuti S, Montevecchi WA (2000) Pursuit plunging by northern gannets (Sula bassana) feeding on capelin (Mallotus villosus). Proc R Soc Lond B 267: $1717-1722$

Gaston AJ, Chapdelaine G, Noble DG (1983) The growth of thick-billed murre chicks at colonies in Hudson Strait: inter- and intra-colony variation. Can J Zool 61:2465-2475

Gotmark F, Winkler DW, Andersson M (1986) Flock-feeding on fish schools increases individual success in gulls. Nature 319:589-591

Grunbaum D, Viet RR (in press) Foraging behaviour of blackbrowed albatrosses exploiting Antarctic krill: densitydependence through local enhancement. Ecology

Guillemette M (1994) Digestive-rate constraints in wintering common eiders (Somateria mollissima): implications for flying capabilities. Auk 111:900-909

Harper DGC (1982) Competitive foraging in mallards: 'ideal free' ducks. Anim Behav 30:575-584

Heinemann D, Hunt GL Jr, Everson I (1989) Relationships between the distributions of marine avian predators and their prey Euphausia superba in Bransfield Strait and southern Drake Passage Antarctica. Mar Ecol Prog Ser $58: 3-16$

Hoffman W, Heinemann D, Wiens JA (1981) The ecology of seabird feeding flocks in Alaska. Auk 98:437-456

Horne JK, Schneider DC (1994) Lack of spatial coherence of predators and prey: a bioenergetic explanation for Atlantic cod feeding on capelin. J Fish Biol 45 (Suppl A):191-207

Horne JK, Schneider DC (1997) Spatial variance of mobile aquatic organisms: capelin and cod in Newfoundland coastal waters. Phil Trans R Soc Lond B 352:633-642

Hughes RN (1997) Diet selection. In: Godin JGJ (ed) Behavioural ecology of teleost fishes. Oxford University Press, New York, p 134-162

Hunt GL Jr, Harrison NM (1990) Foraging habitat and prey taken by least auklets at King Island, Alaska. Mar Ecol Prog Ser 65:141-150

Hunt GL Jr, Eppley ZA, Schneider DC (1986) Reproductive performance of seabirds: the importance of population and colony size. Auk 103:306-317

Hunt GL Jr, Harrison NM, Cooney RT (1991) How do foraging seabirds sample their environment? In: Bell BD, Cossee RO, Flux JEC, Heather BD, Hitchmough RA, Robertson CJR, Williams JF (eds) Acta XX Congressus Internationalis Ornithologici. Ornithological Congress Trust Board, Wellington, p 2272-2279

Huntingford FA (1993) Can cost-benefit analysis explain fish distribution patterns? J Fish Biol 43 (Suppl A):289-308

Irons DB (1998) Foraging area fidelity of individual seabirds in relation to tidal cycles and flock feeding. Ecology 79:647-655

Kacelnik A, Krebs JR, Bernstein C (1992) The ideal free distribution and predator-prey populations. Trends Ecol Evol 7: $50-55$ 
Lewis S, Sherratt TN, Hamer KC, Wanless S (2001) Evidence of intra-specific competition for food in a pelagic seabird. Nature 412:816-819

Logerwell EA, Hewitt RP, Demer DA (1998) Scale-dependent spatial variance patterns and correlations of seabirds and prey in the southeastern Bering Sea as revealed by spectral analysis. Ecography 21:212-223

Maniscalco JM, Ostrand WD, Coyle KO (1998) Selection of fish schools by flocking seabirds in Prince William Sound Alaska. Colon Waterbirds 21:314-322

Maniscalco JM, Ostrand WD, Suryan RM, Irons DB (2001) Passive interference competition by glaucous-winged gulls on black-legged kittiwakes: a cost of feeding in flocks. Condor 103:616-619

Mehlum F, Hunt GL Jr, Klusek Z, Decker MB, Nordlund N (1996) The importance of prey aggregations to the distribution of Brunnich's guillemots in Storfjorden, Svalbard. Polar Biol 16:537-547

Milinski M (1994) Long-term memory for food patches and implications for ideal free distributions in sticklebacks. Ecology 75:1150-1156

Milinski M, Parker GA (1991) Competition for resources. In: Krebs JR, Davies NB (eds) Behavioural ecology: an evolutionary approach. Blackwell Scientific, Oxford, p 137-168

Montevecchi WA (2000) Seabirds. In: Bundy A, Lilly GR, Shelton PA (eds) A mass balance model of the Newfoundland-Labrador Shelf. Can Tech Rep Fish Aquat Sci 2310:15-18

Montevecchi WA, Piatt JF (1984) Composition and energy contents of mature inshore spawning capelin (Mallotus villosus): implications for seabird predators. Comp Biochem Physiol 78:15-20

O'Driscoll RL (1998) Description of spatial pattern in seabird distributions along line transects using neighbour K statistics. Mar Ecol Prog Ser 165:81-94

O'Driscoll RL, Schneider DC, Rose GA, Lilly GR (2000) Potential contact statistics for measuring scale-dependent spatial pattern and association: an example of northern cod (Gadus morhua) and capelin (Mallotus villosus). Can J Fish Aquat Sci 57:1355-1368

Orians GH, Pearson NE (1979) On the theory of central place foraging. In: Horn DJ, Mitchell RD, Stairs GR (eds) Analyses of ecological systems. Ohio State University Press, Columbus, p 154-177

Parker GA, Sutherland WJ (1986) Ideal free distribution when individuals differ in competitive ability: phenotypelimited ideal free models. Anim Behav 34:1222-1242

Piatt JF (1990) The aggregative response of common murres and Atlantic puffins to schools of capelin. Stud Avian Biol $14: 36-51$

Piatt JF, Nettleship DN (1984) Diving depths of four alcids. Auk 102:293-297

Editorial responsibility: Otto Kinne (Editor),

Oldendorf/Luhe, Germany
Pinel JPJ (1997) Biopsychology. Allyn \& Bacon, Toronto Ripley BD (1981) Spatial statistics. John Wiley \& Sons, New York

Sanford RC, Harris SW (1967) Feeding behavior and foodconsumption rates of a captive California murre. Condor 69:298-302

Schneider DC, Piatt JF (1986) Scale-dependent correlation of seabirds with schooling fish in a coastal ecosystem. Mar Ecol Prog Ser 32:237-246

Schneider DC, Harrison NM, Hunt GL Jr (1987) Variation in the occurrence of marine birds at fronts in the Bering Sea. Estuar Coast Shelf Sci 25:135-141

Stillman RA, Goss-Custard JD, Clarke RT, Dit Durell SEALV (1996) Shape of the interference function in a foraging vertebrate. J Anim Ecol 65:813-824

Sutherland WJ (1983) Aggregation and the 'ideal free' distribution. J Anim Ecol 52:821-828

Swennen C, Duiven P (1991) Diving speed and food-size selection in common guillemots Uria aalge. Neth J Sea Res 27:191-196

Tasker ML, Hope Jones P, Dixon T, Blake BF (1984) Counting seabirds at sea from ships: a review of methods employed and a suggestion for a standardized approach. Auk 101:567-577

Thompson CW, Wilson ML, Melvin EF, Pierce DJ (1998) An unusual sequence of flight-feather molt in common murres and its evolutionary implications. Auk 115:653-669

Tregenza T (1995) Building on the ideal free distribution. Adv Ecol Res 26:253-307

Veit RR, Silverman ED, Everson I (1993) Aggregation patterns of pelagic predators and their principal prey Antarctic krill near South Georgia. J Anim Ecol 62:551-564

Wanless S, Harris MP, Morris JA (1990) A comparison of feeding areas used by individual common murres (Uria aalge) razorbills (Alca torda) and an Atlantic puffin (Fratercula arctica) during the breeding season. Colon Waterbirds 13:16-24

Wanless S, Bacon PJ, Harris MP, Webb AD, Greenstreet SPR, Webb A (1997) Modelling environmental and energetic effects on feeding performance and distribution of shags (Phalacrocorax aristotelis): integrating telemetry geographical information systems and modeling techniques. ICES J Mar Sci 54:524-544

Wittenberger JF, Hunt GL Jr (1985) The adaptive significance of coloniality in birds. In: Farner DS, King JR, Parkes KC (eds) Avian biology, Vol 8. Academic Press, Toronto, p 1-77

Ydenberg RC, Clark CW (1989) Aerobiosis and anaerobiosis during diving by Western Grebes: an optimal foraging approach. J Theor Biol 139:437-449

Ydenberg RC, Forbes LS (1988) Diving and foraging in western grebes. Ornis Scandinavica 19:129-133

Submitted: May 24, 2002; Accepted: April 4, 2003

Proofs received from author(s): July 4, 2003 